\title{
New Methodological Approach Towards a Complete Characterization of Structural Fiber Reinforced Concrete by Means of Mechanical Testing Procedures
}

\author{
Marcos G. Alberti ${ }^{1}$, Álvaro Picazo ${ }^{2}$, Jaime C. Gálvez ${ }^{1, *}$ and Alejandro Enfedaque ${ }^{1}$ \\ 1 Departamento de Ingeniería Civil: Construcción, E.T.S de Ingenieros de Caminos, Canales y Puertos, \\ Universidad Politécnica de Madrid, C/Profesor Aranguren, s/n, 28040 Madrid, Spain; \\ marcos.garcia@upm.es; jaime.galvez@upm.es; alejandro.enfedaque@upm.es; \\ 2 Departamento de Tecnología de la Edificación, E.T.S de Edificación, Universidad Politécnica de Madrid, \\ Avda. Juan de Herrera, 6, 28040 Madrid, Spain; a.picazo@upm.es \\ * Correspondence: jaime.galvez@upm.es; Tel.: +34-91-0674-125
}

\begin{abstract}
This work proposes a novel methodology for the complete characterization of fiber reinforced concrete (FRC). The method includes bending tests of prismatic notched specimens, based on the Standards for FRC, tensile and pure shear tests. The values adopted by the standards for designing FRC are the obtained from bending tests, typically $f_{R 3}$, even for shear and pure tension loading. This paper shows that the remaining strength of FRC, supplied by the fibers, depends on the type of loading. In the case of shear and tensile loading the prescriptions of the standards may be unsafe. In this work, the remaining halves of specimens subjected to bending test are prepared and used for shear and tension tests. This means significant savings in specimen preparation and a greater amount of information for structural use of FRC. The results provide relevant information for the design of structural elements of FRC compared with the only use of data supplied by bending tests. In addition, a video-extensometry system was used to analyze the crack generation and cracking patterns. The video-extensometry applied to shear tests allowed the assessment of the sliding values and crack opening values at the crack discontinuity. These values may be quite relevant for the study of the FRC behavior when subjected to shear according to the shear-friction model theories.
\end{abstract}

Keywords: fiber reinforced concrete; direct tensile test; push-off test; polyolefin fiber; digital image correlation

\section{Introduction}

Fiber-reinforced concrete (FRC), with fibers randomly distributed in the mass, improves plain concrete tensile strength, increases its ductility and reduces cracking at early ages [1,2]. This aspect improves durability and reduces the maintenance costs.

There are various types of fibers designed for the reinforcement of concrete: steel, glass, polymeric and natural ones, among others. Some of them might provide structural characteristics to FRC [3-7]. Some concrete Standards [8-12] include the use of steel and polymer macro fibers for structural purposes if certain requirements are met. This may enable the reduction of the rebar reinforcement ratio in reinforced concrete, both for bending and shear [13-15], while reducing cracking [16, 17], and in particular the width of macro cracks.

The use of structural fibers allows partial replacement of the bending reinforcement and the total or partial replacement of the shear reinforcement [20-22]. This results in a significant reduction in labor and construction time.

Traditionally, steel fibers have been the most used ones for structural fiber reinforced concrete, but recently polymeric macro fibers have been developed seeking an alternative to steel fibers. Such fibers provide as main advantages: corrosion resistance [19], weight reduction and reduced deterioration of the construction machinery [18]. 
Structural concrete standards consider the structural contribution of fiber reinforcement from bending tests carried out with prismatic notched specimens [23-24]. Model Code 2010 [8] and the Spanish Structural Concrete Standard (EHE-08) [12] consider as fiber-reinforced concrete with structural character one that meets two residual strength values in the bending tests: its stress for a crack mouth opening displacement (CMOD) of $0.5 \mathrm{~mm}\left(f_{R 1}\right)$, should be greater than $40 \%$ of the stress in the limit of proportionality ( $\left.f_{L O P}\right)$ and, in addition, the for a $2.5 \mathrm{~mm}$ CMOD stress $\left(f_{R 3}\right)$, must be greater than $20 \%$ of the $f_{L O P}$. Structural design of fiber-reinforced concrete, provided by structural concrete standards, is based on both bending residual stresses $f_{R 1}$ and $f_{R 3}$.

For the evaluation of the strength of fiber-reinforced concrete under different loading conditions, such as tensile and shear, the value of $f_{R 3}$ is adopted according to the mentioned structural concrete Standards [8, 12]. However, it seems more appropriate to perform shear or tensile tests when the main stresses that FRC ought to bear is one of such. A recent study has shown that the shear strength of fiber-reinforced concrete stipulated by the standards may differ from that obtained from a pure shear test [37]. In addition, the reinforcing mechanisms of the fibers when subjected to shear strength differ according to their characteristics, especially if steel fibers and polymeric ones are compared [26].

This study proposes a methodology based on the use of the prismatic notched specimens for bending tests, which supply $f_{R 1}$ and $f_{R 3}$, to perform, from its two halves, tensile and pure shear tests. In such a way the complete characterization of fiber-reinforced concrete is obtained under bending, tensile and shearing loading, without the need to produce new specimens.

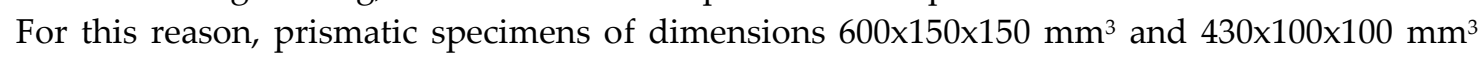
were performed and tested under bending conditions [23, 24]. The results of these tests confirmed structural capacity of the fiber-reinforced concretes. The remaining halves of the specimens were machined for direct tensile and pure shear testing.

In addition, a video-extensometry system was used, which allowed to obtain the cracking patterns of the specimens during the whole tests. It is worth noting that this technique does not produce any interference with the test, and allows to observe the generation, nucleation and growth of the cracks when they are imperceptible with the naked eye.

Table 1. Component data $\left(\mathrm{kg} / \mathrm{m}^{3}\right)$ for the mixes used in the experimental campaign.

\begin{tabular}{cccccc}
\hline Materials & SCCP6 & VCCP6 & VCLP6 & VCCP10 & SCCS70 \\
\hline Cement 52.5 & 375 & 375 & -- & 375 & 425 \\
Cement 32.5 & -- & -- & 312 & -- & -- \\
Water & 188 & 188 & 216 & 188 & 199 \\
w/c & 0.50 & 0.50 & 0.69 & 0.50 & 0.47 \\
Sand & 918 & 916 & 875 & 916 & 947 \\
Grit & 245 & 300 & 198 & 300 & -- \\
Gravel & 367 & 450 & 519 & 450 & 486 \\
Limestone & 200 & 100 & -- & 100 & 210 \\
Superplasticizer & 4.7 & 2.8 & -- & 3.1 & 5.6 \\
Fiber P48 $\left(V_{f} \%\right)$ & -- & -- & 0.66 & -- & -- \\
Fiber P60 $\left(V_{f} \%\right)$ & 0.66 & 0.66 & -- & 1.10 & -- \\
Fiber S35 $\left(V_{f} \%\right)$ & -- & -- & -- & -- & 0.44 \\
Fiber S50 $\left(V_{f} \%\right)$ & -- & -- & -- & -- & 0.44 \\
Compacting & Self- & Vibrated & Vibrated & Vibrated & Self- \\
& compacting & conventional & conventional & conventional & compacting \\
\hline
\end{tabular}

\section{Materials}


The mix proportioning of the types of concrete used in the experimental campaign is shown in Table 1 and the basic properties and denominations are described in Figure 1. Four concrete types were prepared with polyolefin fibers and were either self-compacting (SCCP6 with $6 \mathrm{~kg} / \mathrm{m}^{3}$ fiber content) or compacted by vibration (VCCP6 and VCLP6 both with $6 \mathrm{~kg} / \mathrm{m}^{3}$ fiber content and VCCP10 with $10 \mathrm{~kg} / \mathrm{m}^{3}$ of fibers). Type VCLP6 is a low compressive strength concrete. Additionally, a selfcompacting type with $70 \mathrm{~kg} / \mathrm{m}^{3}$ of steel fibers was prepared. The properties of the components and the manufacturing procedures are the ones described in previous studies [18, 27, 28]. The characteristics of polyolefin (Sika) and steel fibers (Bekaert) are listed in Table 2.

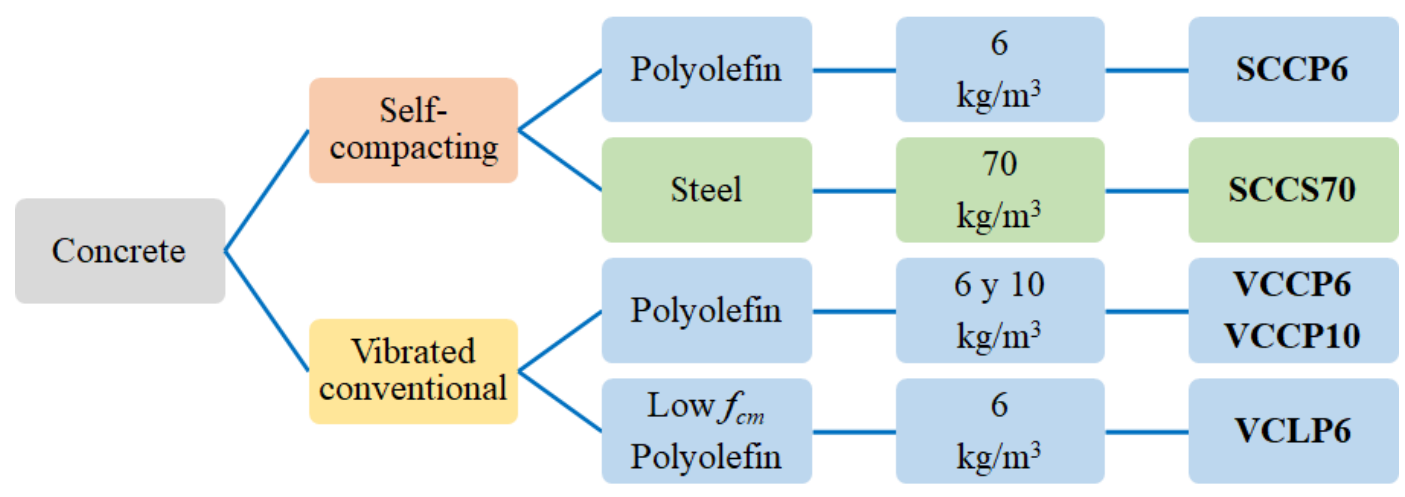

Figure 1. Used concrete types.

Table 2. Properties of fibers.

\begin{tabular}{ccccc}
\hline & P48 & P60 & S35 & S50 \\
\hline Density $\left(\mathrm{g} / \mathrm{cm}^{3}\right)$ & 0.91 & 0.91 & 7.85 & 7.85 \\
Length $(\mathrm{mm})$ & 48 & 60 & 35 & 50 \\
Eq. $\varnothing(\mathrm{mm})$ & 0.903 & 0.903 & 0.550 & 0.600 \\
Aspect ratio (L/D) & 53 & 66 & 64 & 83 \\
Tensile strength $(\mathrm{MPa})$ & $>400$ & $>500$ & 1100 & 1100 \\
Modulus of elasticity $(\mathrm{GPa})$ & $>6$ & $>9$ & 210 & 210 \\
Fibers per kg & 32895 & 27000 & 14500 & 8500 \\
Surface structure & Rough & Rough & Smooth & Smooth \\
\hline
\end{tabular}

\section{Specimen preparation and testing procedures}

\subsection{Three-point bending tests on notched specimens}

Two specimen sizes were used for bending tests: large prisms of 600x150x150 $\mathrm{mm}^{3}$ and small

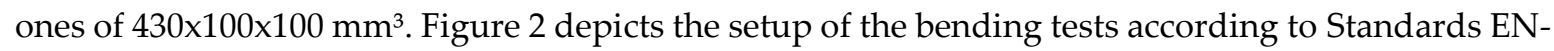
14651 and RILEM TC-162-TDF [23, 24] and the results were reported in [18, 27, 28]. According to the experimental results and the criteria of codes MC-2010 and EHE-08 all concrete types showed structural capacity. 


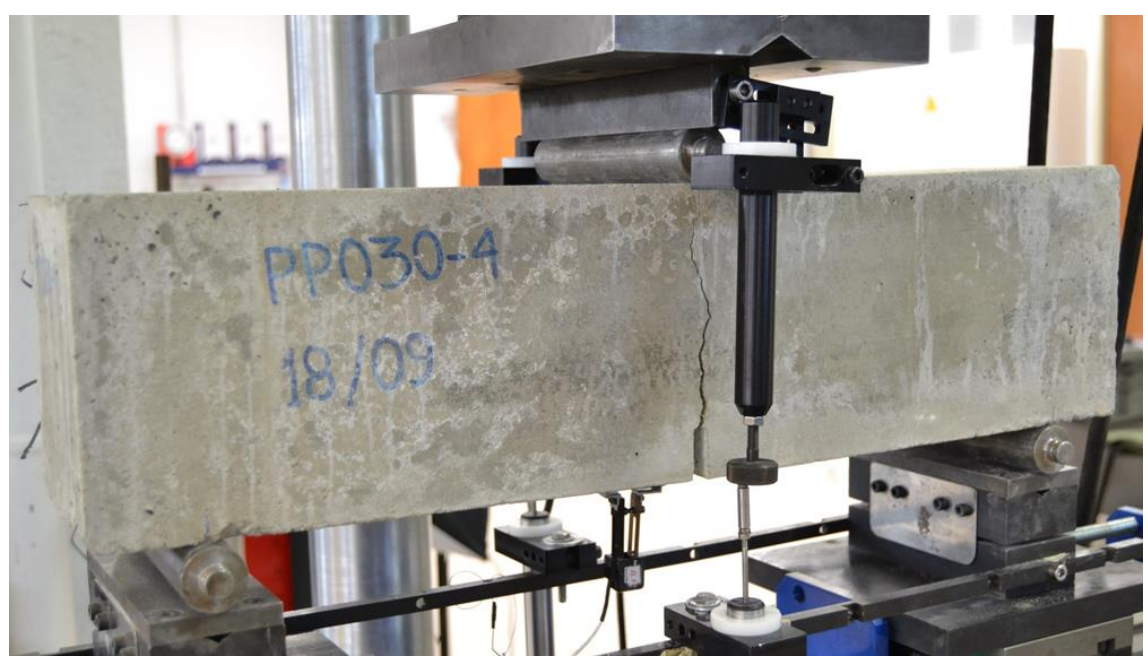

Figure 2. Three-point bending test.

The bending tests proceeded until two halves were obtained which were later used for tensile and shear tests as shown in Figure 3.

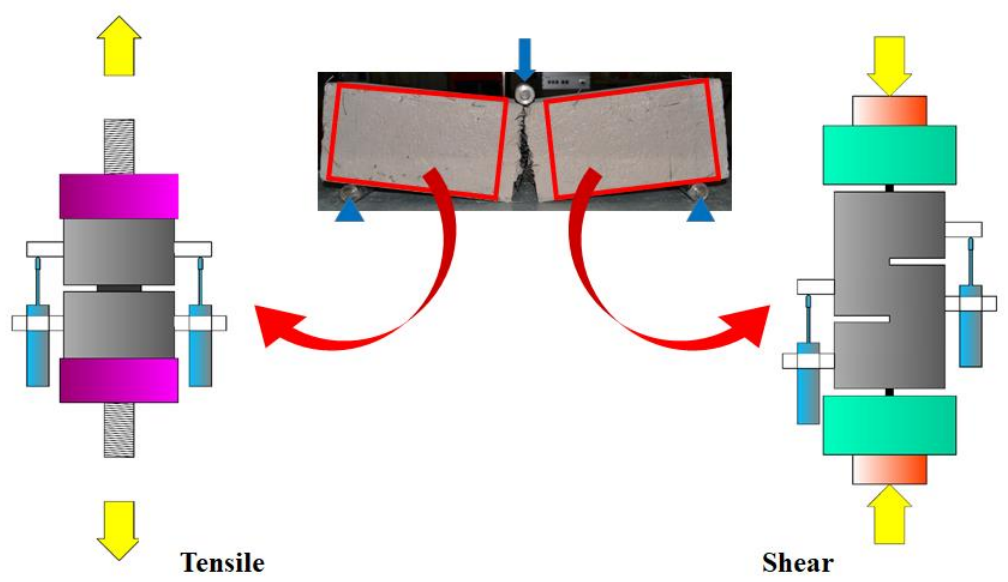

Figure 3. Obtaining specimens for tensile and direct shear tests.

\subsection{Tensile strength tests}

Concrete types SCCP6, VCCP6 and VCLP6 were used for tensile strength tests. The halves obtained in the bending tests were adapted to the tensile tests by carefully eliminating concrete portions close to the bending fracture surface and the opposite side. This way, prismatic specimens

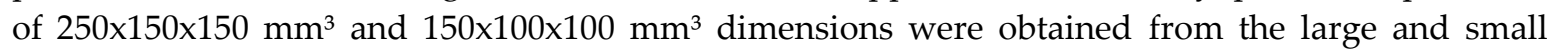
samples respectively. The sample sides in contact with the testing machine were grinded to create flat and parallel surfaces. With the help of a water-refrigerated diamond disc, a perimetral notch was cut at mid length as shown in Figure 4(a) being 8-mm and 2-mm deep in large and small specimens, respectively. Consequently, the ligament section was $60 \times 60 \mathrm{~mm}^{2}$ for all specimens allowing a direct comparison of the experimental results.

Then, steel caps, as shown in Figure 4(a), were glued to each end of specimens. This was achieved by means of a high-strength two-component epoxy resin with a curing time of $24 \mathrm{~h}$ at room temperature. Then the specimens were painted in black with several white spots. The inside of the notch in the rear face of the specimens was painted with a monochrome pattern of random distributed points $[29,30]$. These two types of painting generated a speckle pattern that allowed the further study of the tests by video-extensometry. 


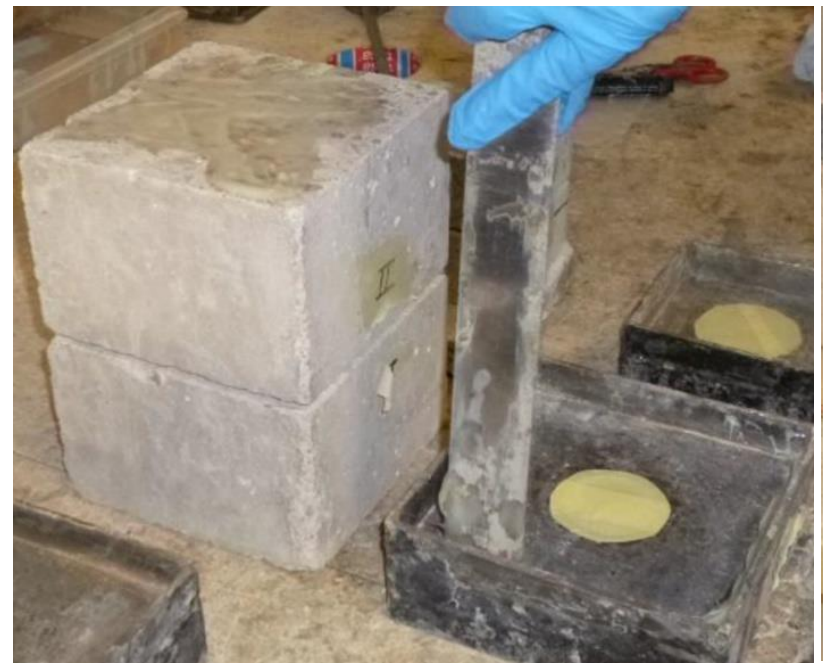

(a)

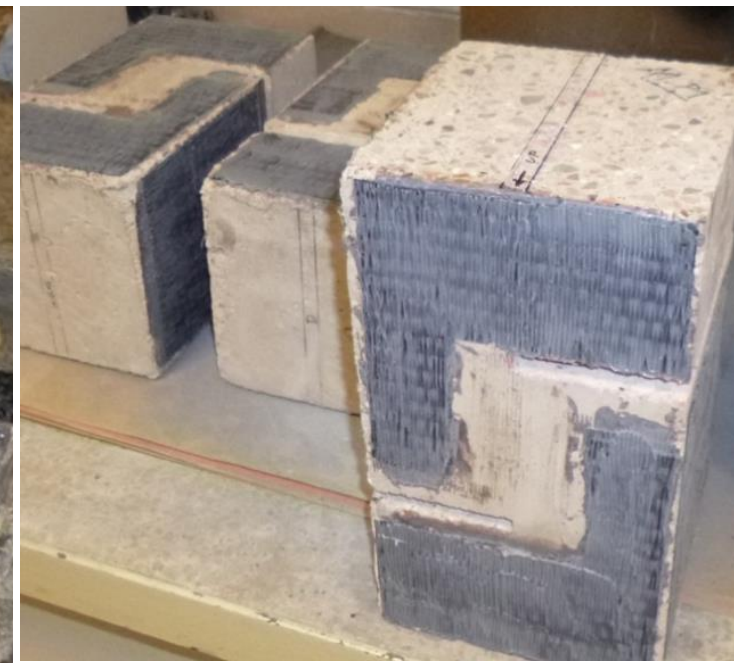

(b)

Figure 4. (a) Notched tensile test specimen and cap. (b) External carbon fibre fabric reinforcement glued to the direct shear test specimen face.

Specimens were attached to the lower part of the testing machine by means of a Dywidag rod. The connection to the top frame of the machine included a ball joint to assure the correct alignment of the tensile forces. The setup can be seen in Figure 5(a).

The tests were performed in a servo-controlled machine (Instron 8803) with $500 \mathrm{kN}$ loading capacity. Two extensometers were placed in the notch tips to measure the opening values. The test was recorded with two high definition cameras of $5 \mathrm{MPx}$. One of them recorded the front side of the specimen in order to detect potential rotations or undesired displacements between cap and specimen. The other one was used to visualize the rear face notch and obtain the nucleation and growth of the cracks. The image record rate was set to one frame per second to enable the synchronization with the testing machine.

Testing was run under displacement control at the speed rates listed in Table 3. These speeds were set so that in every case the first crack of the ligament section would occur in the first test step. The applied load, actuator displacement and change in the distance between the notch tips were recorded. Also, all relevant images of the test development were obtained.

Table 3. Loading rate program of the tension tests.

\begin{tabular}{ccccccccccc}
\hline Step & $\mathbf{1}$ & $\mathbf{2}$ & $\mathbf{3}$ & $\mathbf{4}$ & $\mathbf{5}$ & $\mathbf{6}$ & $\mathbf{7}$ & $\mathbf{8}$ & $\mathbf{9}$ & $\mathbf{1 0}$ \\
\hline $\begin{array}{c}\text { Rate } \\
(\mathrm{mm} / \mathrm{s})\end{array}$ & 0.005 & 0.006 & 0.007 & 0.008 & 0.009 & 0.010 & 0.020 & 0.040 & 0.080 & 0.160 \\
$\begin{array}{c}\text { Displacement } \\
(\mathrm{mm})\end{array}$ & 10 & 0.1 & 0.1 & 0.1 & 0.1 & 0.1 & 0.1 & 0.1 & 0.1 & 30 \\
\hline
\end{tabular}

\subsection{Direct shear tests}

Push-off tests were performed on concrete types VCLP6, VCCP10 and SCCS70. As above commented for the tensile tests, the shear or push-off specimens came from the remaining halves of the bending tests. Specimen ends were trimmed to eliminate the crack affected zones resulting prisms

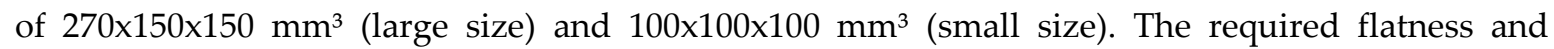
parallelism conditions of the end faces were achieved by careful grinding ensuring the correct performance of the test. Then two notches in opposite faces of the specimens were carved with 9 and $4 \mathrm{~mm}$ thickness and 75- and 50-mm depths for the large and small size specimens, respectively. The height of the ligament section was then 90 and $20 \mathrm{~mm}$ for each specimen size. This way, as can be 
observed in Figure 5, the resisting ligament section through which the shear force is transmitted was located vertically between the notch ends. This careful shaping was also performed with a diamond disc cutting machine.

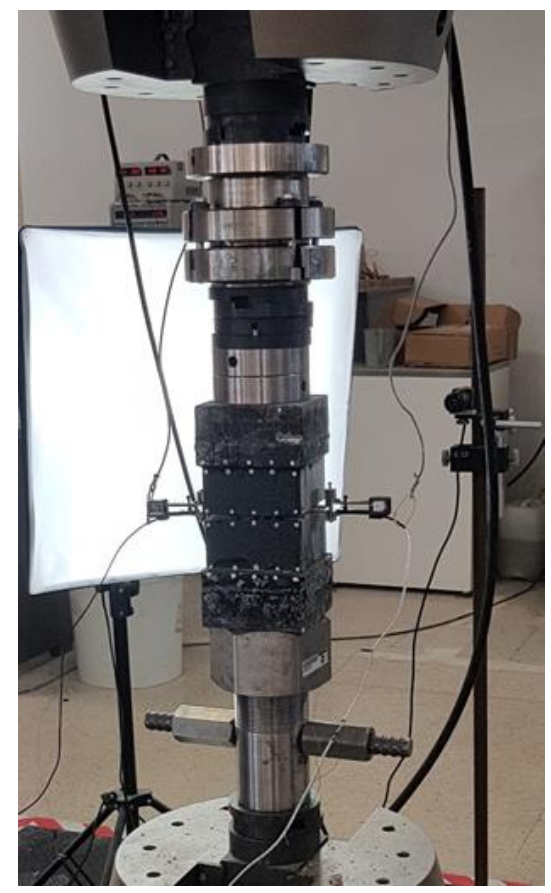

(a)

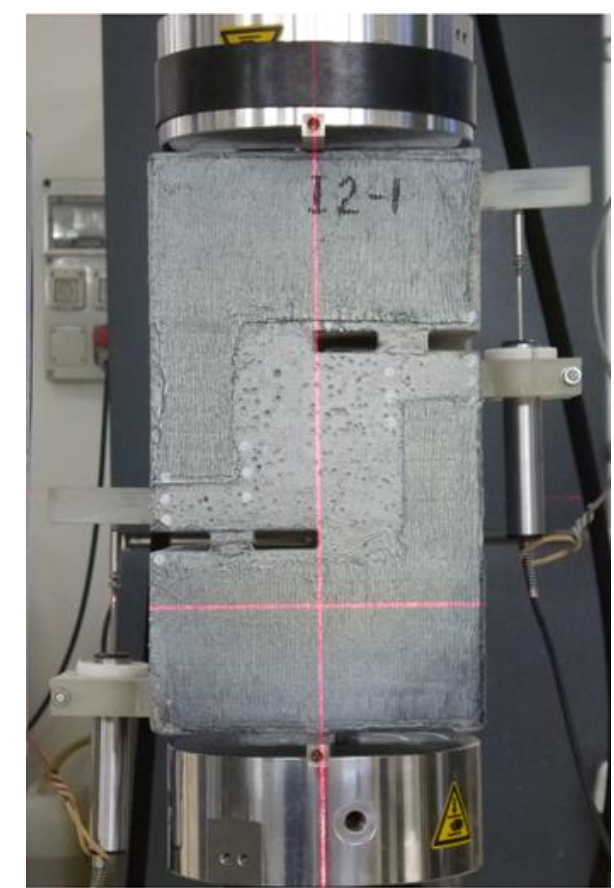

(b)

Figure 5. (a) Tensile test set up (b) Push-off test

Push-off specimens had to be reinforced to avoid undesired bending effects at the time of testing, that is, damages on the upper and lower cantilever portions of the specimen. That was carried out by using unidirectional carbon fiber fabric SikaWrap 300 glued with SikaDur 300 epoxy resin as in Figure 4 (b). This reinforcement showed an excellent performance during the tests preventing undesired failures of the specimen. For the correct implementation of this reinforcement, some of the specimen edges were chamfered with a diamond disc machine in order to avoid stress concentrations in the carbon fabric. After the reinforcement was glued, the front and rear faces of the specimens were painted with a monochromatic pattern with random spots [29, 30] for video-extensometry purposes.

The precise positioning of specimens in the machine was critical for achieving a valid test. For that purpose, a steel bar of $10 \times 10 \mathrm{~mm}^{2}$ section was placed on the lower machine plate. On top of it, the specimen was placed with an equal steel bar. Once the bars and specimen were placed the bars and the inside ends of the notches were aligned vertically with the help of a laser levelling device as in Figure 5 (b).

Two extensometer devices were placed on the notch external tips to assess the opening or closing of the gap during the testing time. The same Instron 8803 testing machine was used. High definition cameras were utilized to monitor the deformations of the rear and front edges of the ligament section, whole process synchronized with the testing machine at one frame per second. The test speed was set at $0.001 \mathrm{~mm}$ per second. The recorded data were the applied load, actuator displacement, change in notch tips distance and the video recording.

\section{Results and discussion}

After detailing how to carry out the methodology of bending, tensile and shear tests through the use of a single specimen, the results obtained are presented. In addition, the comparison between experimental results and design values proposed by the Standards CM-2010 and EHE-08 $[8,12]$ is included. The displacement assessment obtained by using video techniques is also compared with 
the obtained by using extensometry, which would allow the validation of video-recording technique in order to be used testing materials such as fiber reinforced concrete [31].

\subsection{Tensile tests}

Figure 6(a) shows the load-displacement curves of three specimens of each type of concrete under tensile testing. In all cases the cross section was $60 \times 60 \mathrm{~mm}^{2}$. For the three concretes analyzed the load-displacement curve shows quite similar behavior: a first linear load branch until reaching the maximum load value $\left(F_{L O P}\right)$, at which point the initial cracking of the specimens occurred. The second branch is a descending stretch with high negative slope to the minimum load point $\left(F_{M I N}\right)$. From this point the remaining load increases as the displacement increases, up to the maximum remaining load value (FREM).

The first branch is associated with the strength of concrete matrix, while the residual loads are governed by the resistant capacity of the fibers. Load variation in FMIN ranged from 0.55 to $1.57 \mathrm{kN}$, while this difference significatively increased for $F_{R E M}$, with values of $3.02 \mathrm{kN}$ for SCCP6, $5.19 \mathrm{kN}$ for VCCP6 and $1.10 \mathrm{kN}$ for VCLP6. As it can be seen, the length of the fibers and the compaction procedure employed considerably affected the remaining load strength of the fiber reinforced concrete.

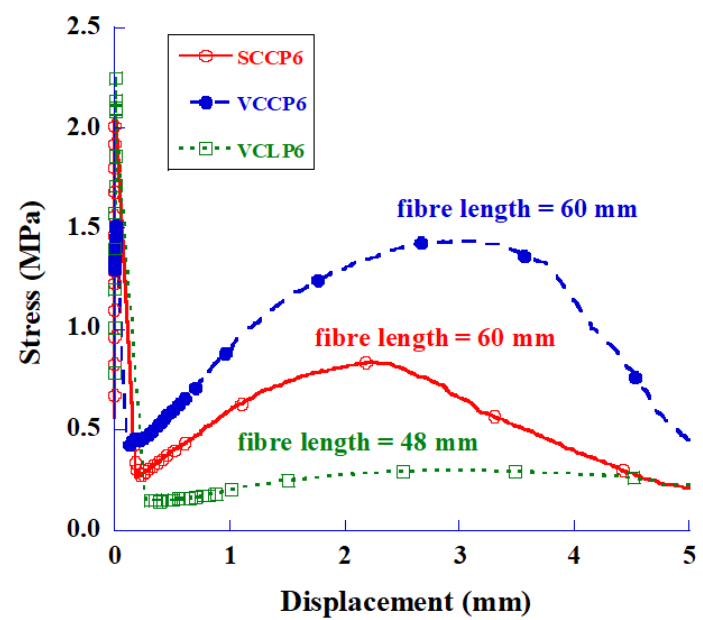

(a)

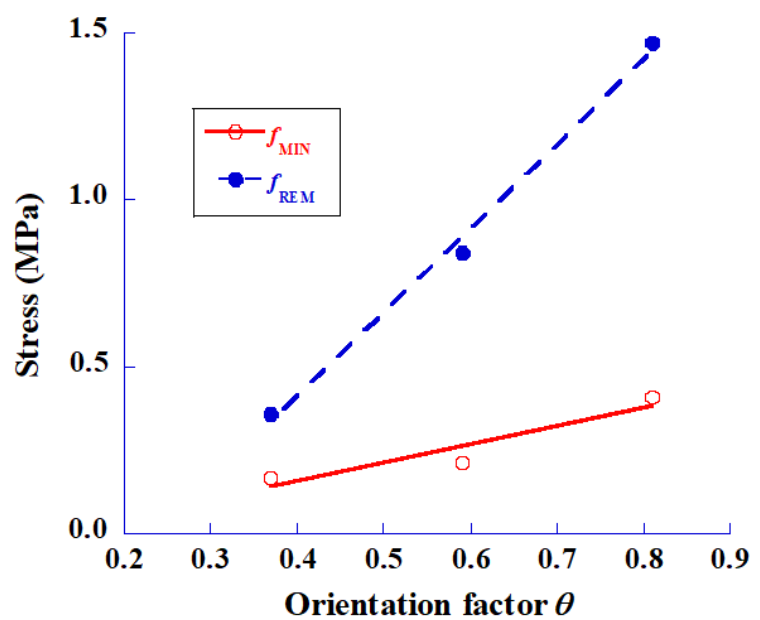

(b)

Figure 6. (a) Stress-displacement curves of tensile tests. (b) Orientation factor-stress curves of tensile test.

Figure 6(b) shows the influence of the coefficient of orientation of fibers in the minimum load value $\left(F_{M I N}\right)$ and the maximum remaining load value $\left(F_{R E M}\right)$. The coefficient of orientation of the fibers is supplied by equation (1) [32]. To this end, the number of fibers in the fracture section was counted and related to the theoretical number of fibers that should exist in that cross section. It can be concluded that the orientation of the fibers plays a primary role in the post-cracking behavior of the fiber reinforced concrete.

$$
\theta=\frac{n}{t h}=\frac{n A_{f}}{V_{f} A_{c}}
$$

where $n$ is the number of fibers counted in the cross section, th the theoretical number of fibers in that section, $A_{f}$ the cross-section area of a fiber, $V_{f}$ the volumetric fraction of fibers and $A_{c}$ the area of the cross section of fiber reinforced concrete. 
In addition, the experimental assessment of displacement, obtained using extensometers, are compared with the one registered by video extensometry. Figure 7 (a) shows the linear variable differential transformer (LVDT) placed in the specimen surface in order to assess the relative displacements between the lips of the notch. White dots were painted on the area above and under the notch of the front face of the specimens, as shown in Figure 7(a). Video-extensometry was able to measure the relative distances between the centers of gravity of the aforementioned white dots during the test. Figure 7(b) shows the evolution of the relative distance of the white dots during testing. In this image, the top points correspond to the position of the points drawn above the notch, while the vertical lines represent the displacement of the points marked right under the notch along the test. This technique was able to check the absence of unexpected rotations during testing. Additionally, other white dots were painted at the upper and lower ends of the specimen and on the metal caps. The absence of relative displacements between the points of the specimen and the caps allowed to ensure the correct adhesion between them and confirmed that the displacement was concentrated on the ligament of the specimen.

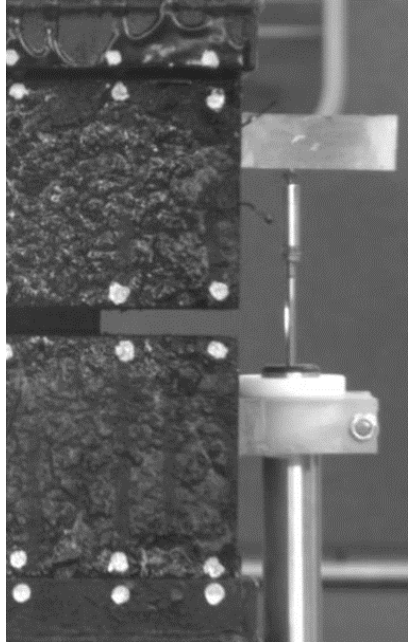

(a)

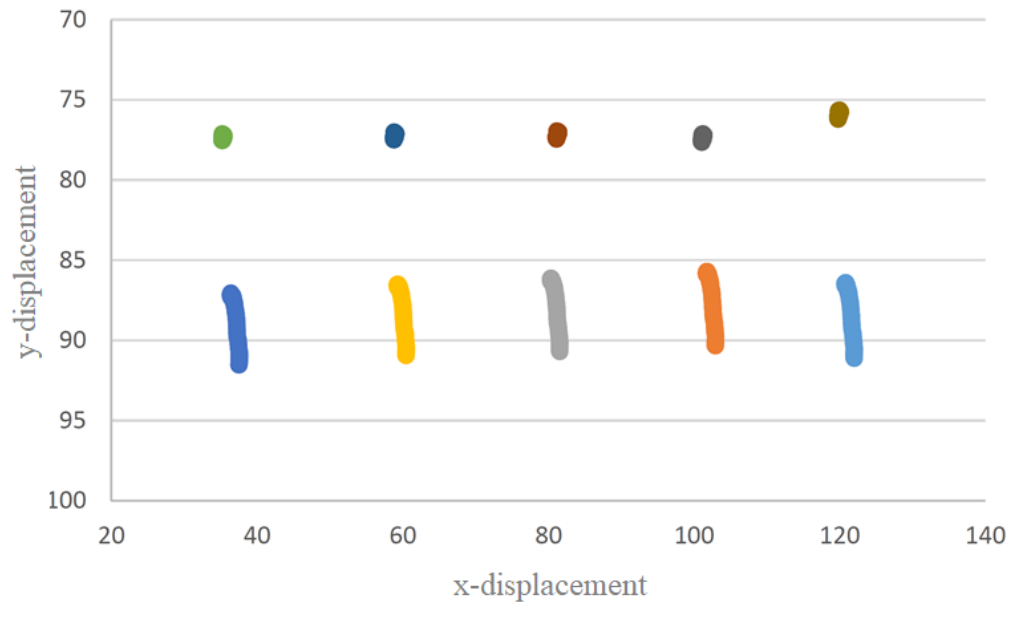

(b)

Figure 7. (a) LVDT placed in the specimen surface for assessing the CMOD. (b) Evolution of the relative position of the white dots placed on both sides of the notch (upper and bottom part) obtained by the video-extensometry.

The high-definition camera placed recording the back of the specimens monitored the pattern of cracks that appeared in the ligament section. The video-extensometry technique allowed to record the strains during testing [33], to observe the nucleation and growth of the cracks when they imperceptible to the naked eye. Figure 8 shows the development of cracks in the ligament during testing. Two cracks appeared in the external part of the ligament, and then both grew symmetrically towards the central area, until the complete fracture of the concrete ligament was achieved. 


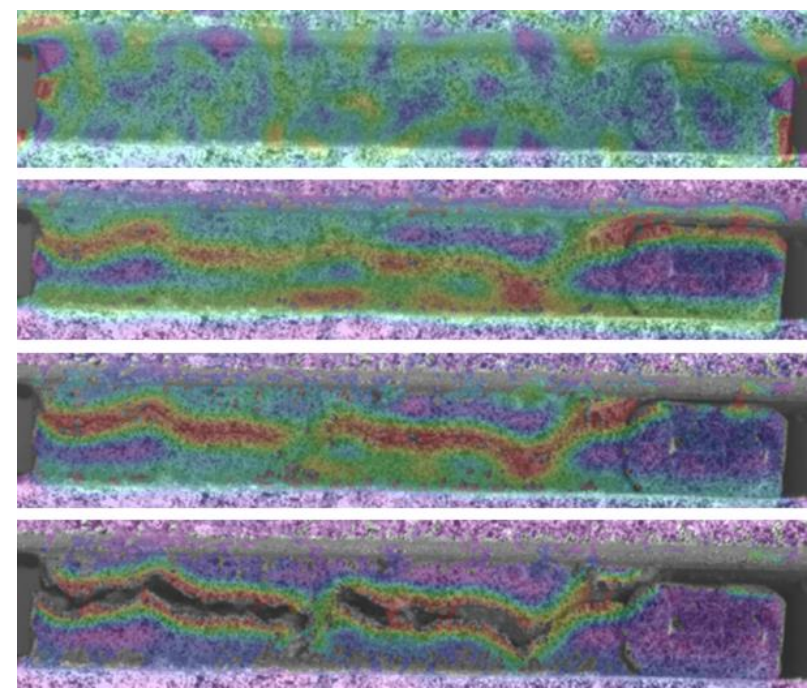

Figure 8. Nucleation and growth of two symmetric cracks in the notched cross section under tensile testing (from upper to bottom photos starting and growth of the cracks).

\subsection{Validation of video-extensometry technic for use in testing}

Video-extensometry techniques are very useful for materials that show cracking during the evolution of testing. They allow to obtain maps of strains, to observe the generation of cracks and to assess their opening during the test, without physical contact with the specimen.

Figure 9 shows the load-displacement curves obtained by the LVDTs extensometers and by video-extensometry in the tensile tests. The values obtained by the video-extensometry match with the values obtained by traditional LVDTs. Figure 9(a) shows the load-displacement curves for SCCP6 concrete, Figure 9(b) for VCCP6, and Figure 9(c) for VCLP6.

\subsection{Comparison of bending and tensile test}

The structural concrete Standards [8, 12] adopt residual strength values supplied by bending tests, $f_{R 1}$ and $f_{R 3}$, as structural designing values of fiber reinforced concrete. Equation (2) show the relation between the force applied by the test machine and the residual strength of the material in the bending test [23].

$$
f_{R}=\frac{3 F l}{b h_{s p}^{2}}
$$

where $f_{R}$ is the stress, $F$ the applied force, $l$ the span between supports, $b$ the width of the specimen and $h_{s p}$ the height of the ligament in the notched section.

In tensile tests the applied force of the testing machine is transformed to stress by dividing the load by the resistant transversal cross section.

Figure 10 shows the $f_{R}$ stress- CMOD curves for bending and tensile tests. Figure 10(a) shows the result for SCCP6, Figure 10(b) VCCP6, and Figure 10(c) for VCLP6 concrete. 


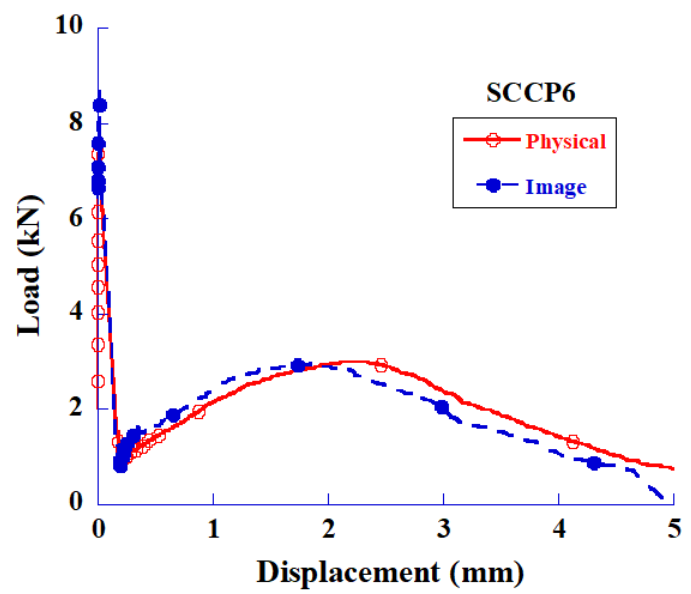

(a)

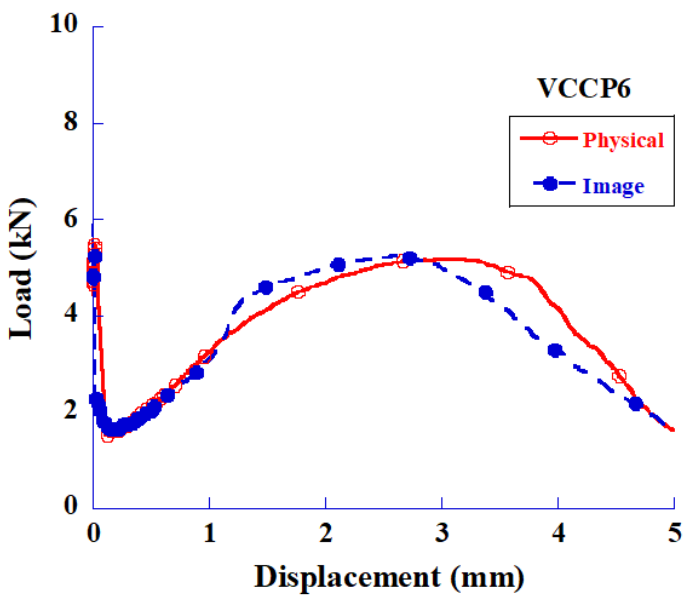

(b)

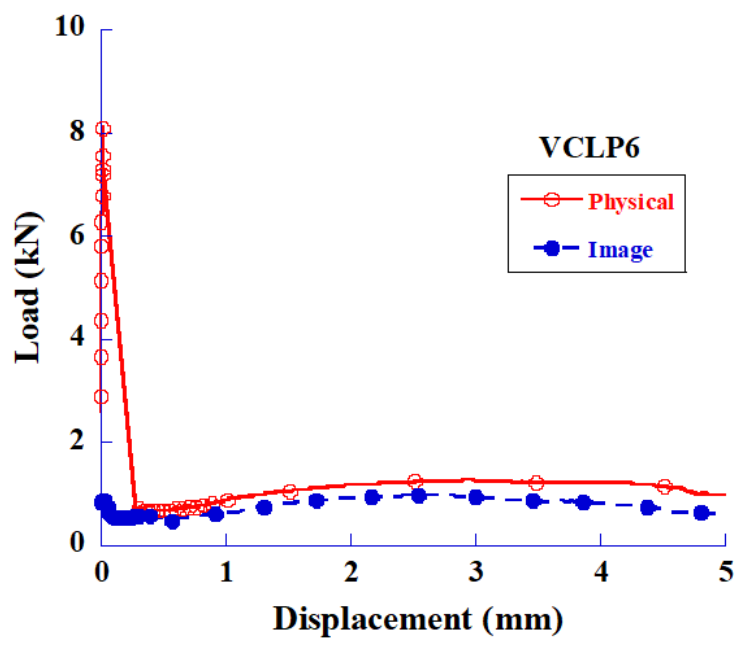

(c)

Figure 9. Load-displacement curves obtained by the LVDTs extensometers and by videoextensometry in the tensile tests: (a) SCCP6, (b) VCCP6 and (c) VCLP6 concretes.

A similar behavior is observed for both tests, bending and tensile tests, for each type of concrete. A first linear branch appears from the test onset up to the limit of proportionality, fLOP, when the matrix of concrete cracks. The $f_{L O P}$ is associated with the strength of the concrete matrix. In the case of bending tests, the low-strength concrete, VCLP6, fLOP value was $2.80 \mathrm{MPa}$, compared with $5.98 \mathrm{MPa}$ and 5.37 $\mathrm{MPa}$, corresponding to SCCP6 and VCCP6, respectively. In the case of tensile tests $f_{L O P}$ ranged from $1.63 \mathrm{MPa}$ to $2.27 \mathrm{MPa}$, values representing $42 \%$ of the strength of the equivalent bending results.

After $f_{L O P}$, stress decreases until the minimum resistance point, $f_{M I N}$. Then, the remaining stress increases until $f_{R E M}$ due to the contribution of the fibers. This remaining part of the stress-CMOD curve increases in all concretes, being the increment more subtle in VCLP6. The maximum residual strength for bending tests were: 3.60, 3.24 and 3.89 MPa for SCCP6, VCCP6 and VCLP6, respectively. These values were reduced to $0.87,1.45$ and $0.39 \mathrm{MPa}$ for each type of concrete respectively, being $31 \%$ the average reduction in remaining resistance in comparison with the bending test. 


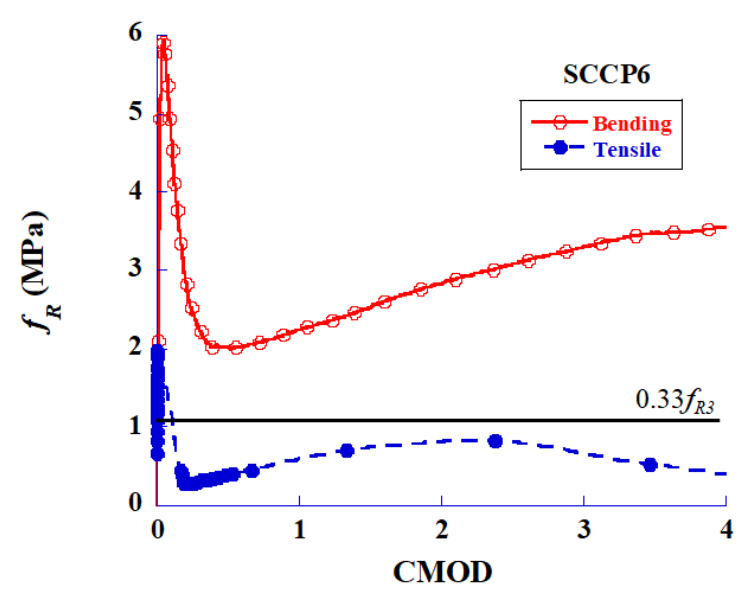

(a)

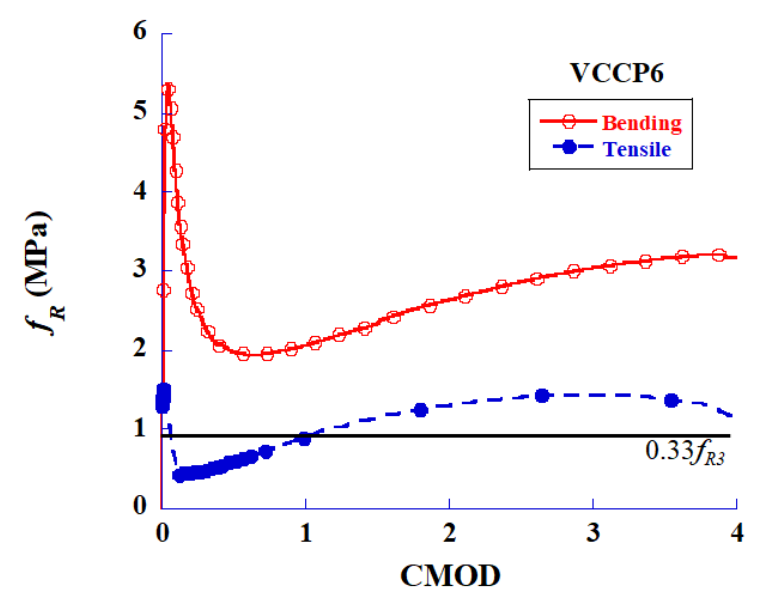

(b)

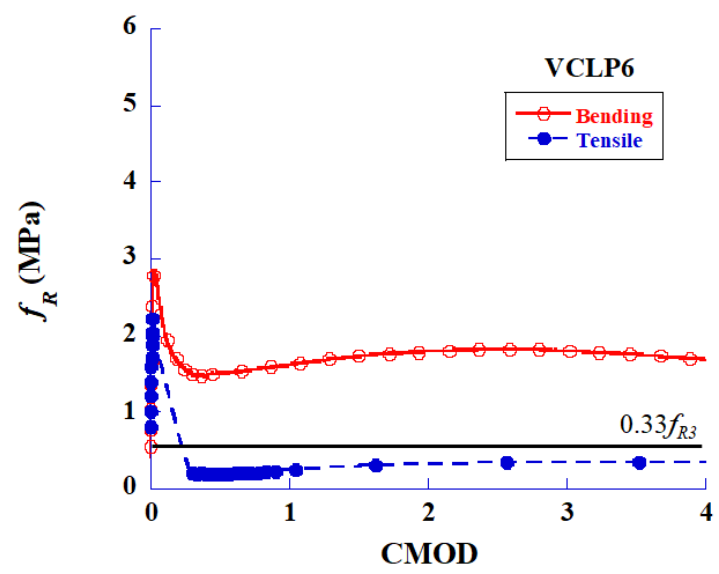

(c)

Figure 10. $f_{R}$ stress- CMOD curves for bending and tensile tests: (a) SCCP6, (b) VCCP6 and (c) VCLP6 concretes

In addition, Figure 10 includes a continuous black line marked as $0.33 f_{R 3}$. This line corresponds to the simplified stress-deformation diagram proposed by EHE-08 [12] for designing structural fiber reinforced concrete. In the case of SCCP6 and VCLP6 concrete, the value $0.33 f_{R 3}$ is higher than the entire residual stress branch, so the standard would overestimate the strength of the fiber reinforced under tensile testing. On the contrary, in the case of VCCP6, from $1 \mathrm{~mm}$ of CMOD, the experimental residual stress is higher than the one prescribed by the EHE-08. The main contribution of tensile tests in relation to bending tests is that they directly show the behavior of fiber reinforced concrete and directly provide values that can be used in the structural design.

\subsection{Push-off shear tests}

Push-off shear tests were carried out with four specimens for VCLP6, three for VCCP10 and two for SCCS70 respectively. All the specimens were monitored on their front and rear face to obtain the cracking patterns in the shear ligament and to assess strain (in bulk sound material) and opening and sliding of the shear cracks.

The first analysis of push-off shear tests results was performed to compare the shear behavior of various concrete types. The nominal resistant area of the ligament was $150 \mathrm{~mm}$ wide by $90 \mathrm{~mm}$ height. After testing, the real area of the ligament was assessed. Figure 11 shows the shear stress (average of experimental results of tested specimens) vs shear sliding in the fracture ligament. The shape of the curves is quite different from the one obtained in the tensile and bending tests.

As in the previous tests, a first straight line of stress increases up to the limit of proportionality, $f_{L O P}$, when the matrix of concrete cracks. The $f_{L O P}$ is associated with the strength concrete matrix. After that, two different behaviors can be observed. For VCCP10 and SCCS70 the curve shows a steep drop 
in the residual shear stress, while for the VCLP6 there is no such abrupt drop. In all cases analyzed, the descending branch did not show a subsequent increase in residual shear stresses, except in the case of SCCS70, with a high amount of steel fibers, in which a slight recovery occurs.

The concrete with the highest ratio of reinforcement shows the highest loss of residual stresses. It is worth noting that for a sliding of $2 \mathrm{~mm}$, the residual stress supported by the concrete with 70 $\mathrm{kg} / \mathrm{m}^{3}$ steel fiber is very similar to the one with of $10 \mathrm{~kg} / \mathrm{m}^{3}$ of polyolefin fibers.

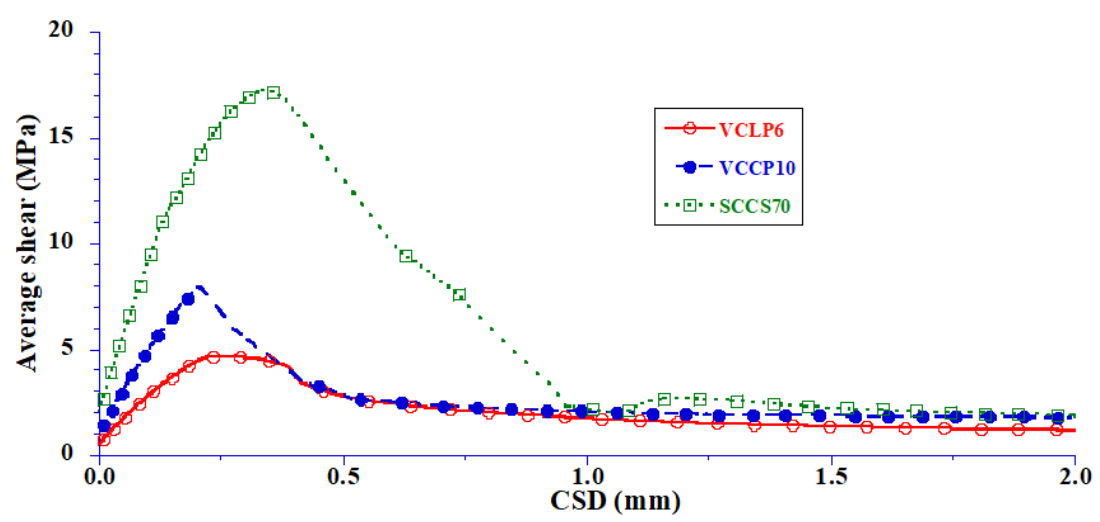

Figure 11. Shear stress (average of experimental results of tested specimens) vs sliding in the ligament for the push-off tests.

\subsection{Comprarison of experimental results with the Standards}

Another analysis to be carried out is the comparison of the CM-2010 and the EHE-08 [8, 12] Standards prescriptions with and the experimental results. As noted above, the shear resistance values calculated according to the Standards are based on the bending residual stress value for 2.5 mm CMOD $\left(f_{R 3}\right)$. Both Standards consider the contribution of fiber reinforcement to the resistance of concrete in an additive way to the shear reinforcement. However, both standards do not consider this contribution in the same way, as it can be seen in equations (3)[8] and (4)[12]. According to CM-2010, the contribution of fibers $\left(f_{F t u k}\right)$ takes the value of $f_{R 3} / 3$, affected by the compression resistance of concrete $\left(f_{c k}\right)$. EHE-08 includes the contribution of the fibers in a term independent of concrete $\left(\tau_{f d}\right)$. This value is considered equal to $0.166 f_{R 3}$. For a more detailed analysis of the formulation, see $[8,12$, 34].

$$
\begin{gathered}
V_{R d, F}=\left\{\frac{0.18}{\gamma_{c}} k\left[100 \rho_{1}\left(1+7.5 \frac{f_{F t u k}}{f_{c t k}}\right) f_{c k}\right]^{1 / 3}+0.15 \sigma_{c p}\right\} b_{w} d \\
V_{r d}=V_{c u}+V_{f u}=\left[\frac{0.18}{\gamma_{c}} \varepsilon\left(100 \rho_{1} f_{c v}\right)^{1 / 3}+0.15{\sigma^{\prime}}_{c d}\right] b_{0} d+0.7 \varepsilon \tau_{f d} b_{0} d
\end{gathered}
$$

Figure 12 shows the comparison of experimental results and analytical values obtained by equations (3) and (4). The values supplied by CM-2010 were adopted as reference values (100\%). Two values of the experimental shear sliding were adopted for comparison: $0.5 \mathrm{~mm}$ and $2.5 \mathrm{~mm}$. In the case of $0.5 \mathrm{~mm}$ of shear sliding, the Standards underestimate the contribution of the fibers to shear, highlighting the contribution of steel fibers, with values five times higher than those of the Standards. For $2.5 \mathrm{~mm}$ of shear sliding, polyolefin fiber reinforcements show higher values of shear strength than steel ones. This different behavior between steel and polyolefin fibers is due to their significant difference in the modulus of elasticity. In addition, the hook end of the steel generates a better behavior for minor sliding. 


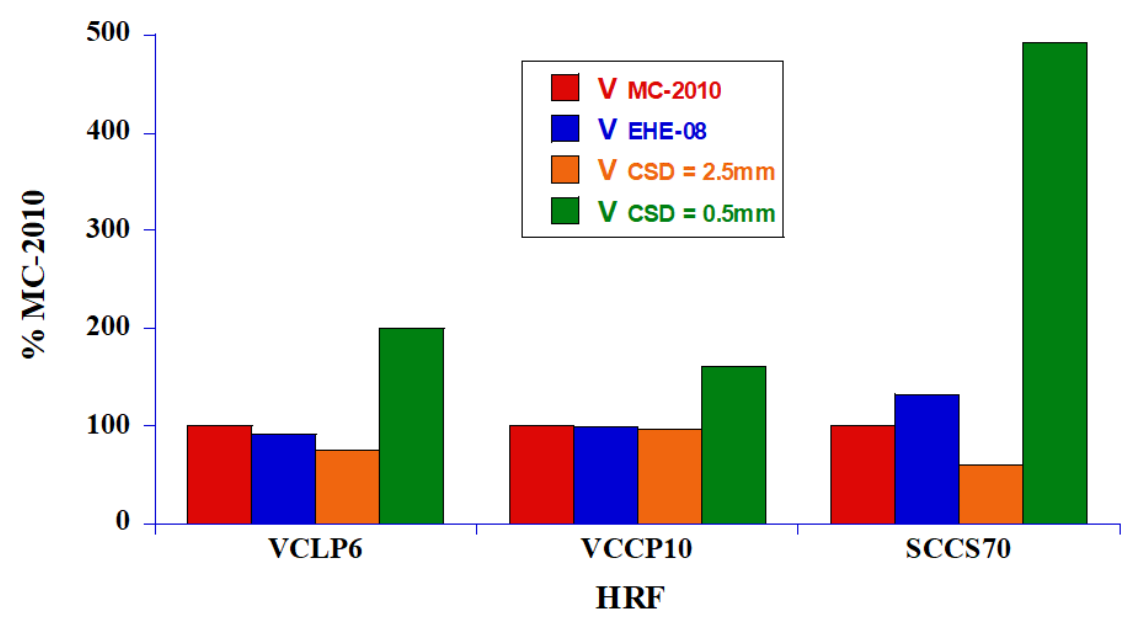

Figure 12. Shear strength of fiber reinforced concrete: according to the Standards $[8,12]$ and experimental, for 0.5 and $2.5 \mathrm{~mm}$ shear sliding.

\subsection{Video-extensometry of the push-off tests}

In addition to the results previously analyzed, a detailed study was carried out regarding the cracking process in the push-off tests with the support of the video-extensometry technique. The time when cracking occurs was different for the three types of concrete. Figure 13(a) shows the point of the first crack in the curve shear stress - crack sliding displacement (CSD). In the case of polyolefin fiber reinforced concrete, it coincides with the highest shear stress. In steel fiber reinforced concrete, the first crack appeared before this point. Figure 13(b) shows a specimen of SCCS70 at the time of cracking. In this figure are marked the shear cracks, placed in the ligament. Additionally, two bending fissures appear out of the resistant ligament. These bending fissures were previously analyzed by using a finite element model [34], and the specimens had to be reinforced externally for avoiding unexpected bending cracking in the cantilevers. As in tensile tests, the video-extensometry system allowed to observe the nucleation and growth of the cracks when they are imperceptible to the naked eye.

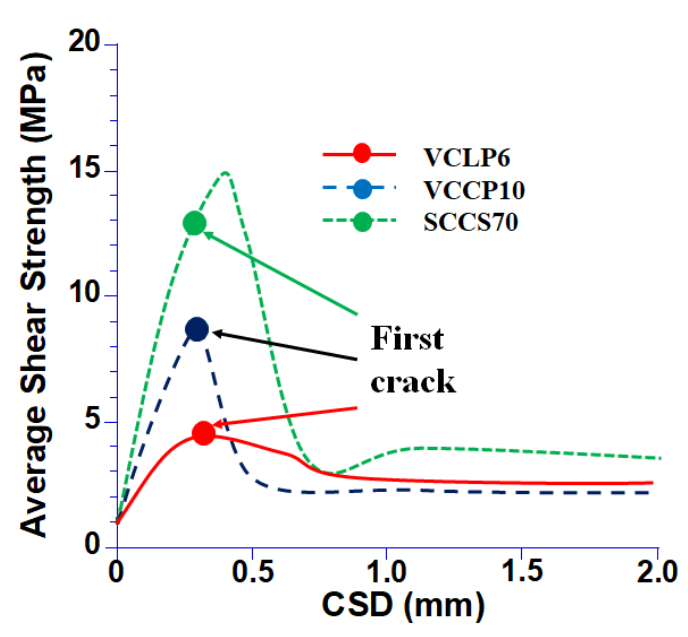

(a)

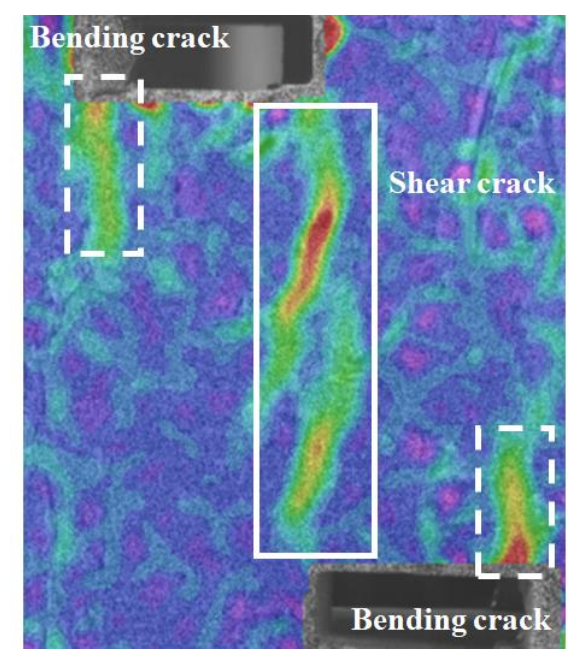

(b)

Figure 13. (a) Curves shear stress vs CSD with the point of the first crack. (b) SCCS70 specimen at the first crack time.

As the tests progressed, the cracks in the ligament developed towards the tips of the notch, while the bending fissures were reduced, even becoming imperceptible. In some cases, the multi-cracking coalesced in a single fracture that connected the tips of the notch, while in other cases there were a multi-cracking pattern with cracks inclined to about $45^{\circ}$ at the end of testing. 
Figure 14(a) shows a VCLP6 specimen at the end of the test, in which the cracking occurred with fissure directions of about $45^{\circ}$, due to the reinforcement of only $6 \mathrm{~kg} / \mathrm{m}^{3}$ of polyolefin fibers. Figure 14(b) shows a VCCP10 specimen at the end of the test, and it can be observed how the pattern and cracking is different, showing a single virtually vertical fissure that joined the tips of the notch. Lastly, Figure 14(c) shows the cracking pattern of a specimen reinforced with steel fibers.

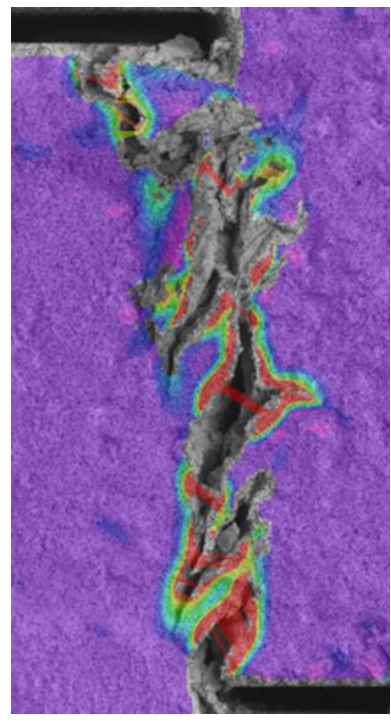

(a)

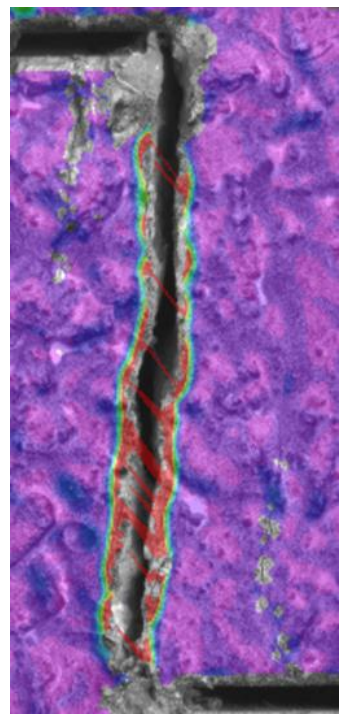

(b)

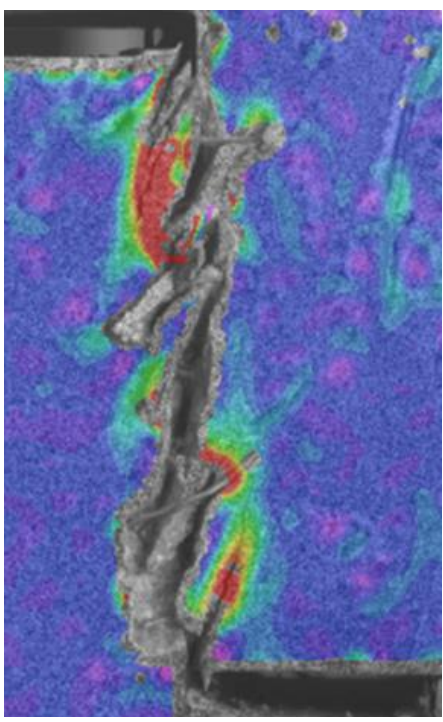

(c)

Figure 14. Crack patterns of the specimens analyzed by video-extensometry: (a) VCLP6, (b) VCCP10 and (c) SCCS70.

The cracking analysis of the push-off specimens was not only focused on the cracking patterns. In addition, the kinematics of the cracks was also studied with video-extensometry technique. Thus, five virtual strain gauges, shown in Figure 15(a), were placed in each specimen. A complex analysis of the recorded data was carried out (note that from each virtual strain gauge about 100 reference points per image are obtained, and that each test lasts more than 4000 seconds, so the system allows the obtaining of 5x100x4000 - 2 million data per test). After analyzing the video-extensometry data, sliding-opening crack curves, such as the one shown in Figure 15(b), could be developed. Such figures are useful for the validation of shear-friction models extended to fiber reinforced concrete [35-37].

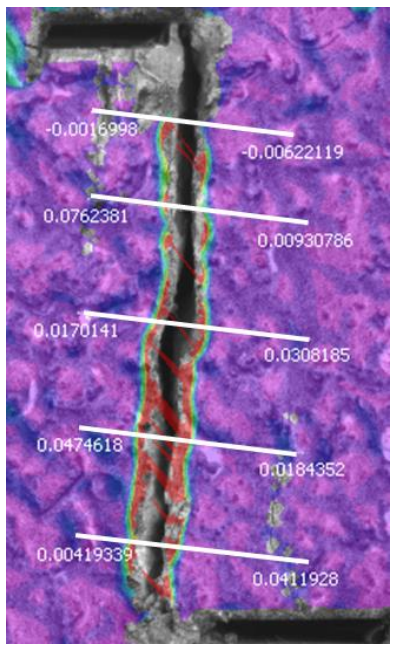

(a)

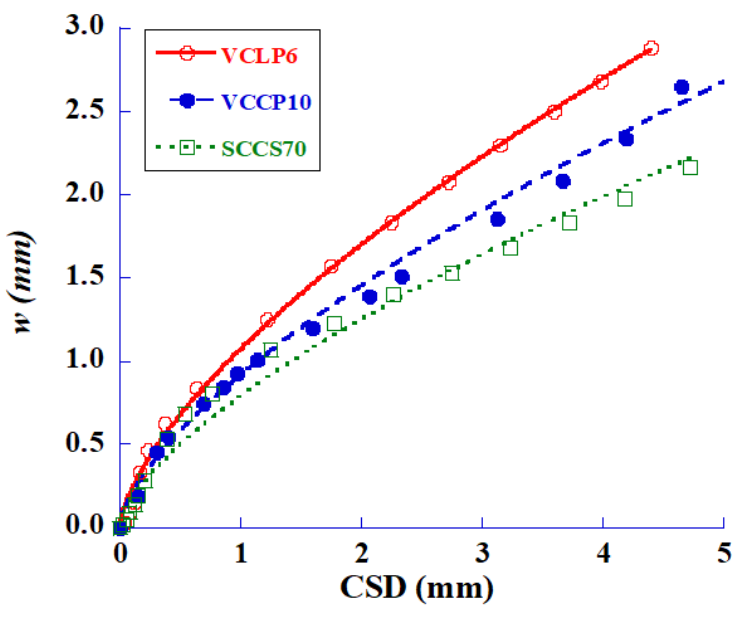

(b)

Figure 15. (a) Virtual strain gauges placed on the ligament of a push-off specimen. (b) slidingopening crack curves obtained by video-extensometry. 


\section{Conclusions}

With the use of a single initial specimen this fiber reinforced concrete (FRC) testing methodology allows carrying out the mechanical characterization of the material by tensile bending strength tests, tensile strength tests, and pure shear strength tests. This means significant savings in specimen preparation and a greater amount of information for the structural use of FRC. For that purpose, the residual halves obtained at the end of the flexural test were used for tensile and direct shear (pushoff) tests and so assess the strength properties of FRC. The test was also monitored by a videoextensometry system in order to analyze the cracking displacements and patterns.

The specimen preparation for direct tensile and shear tests were a quite laborious and care taking process and were more time consuming as compared to the standard testing procedures for FRC. The test setup required a detailed planning and the precise positioning to prevent undesired stresses in the specimens. However, the results provide relevant information for the design of structural elements of FRC compared with the only use of bending tests.

The video-extensometry system requires a previous preparation of the specimens, the correct positioning of the cameras, adequate lighting and precise focusing. The results obtained with this technique are similar to the ones provided by physical extensometers but involves a complex data processing. On the contrary, it should be underlined that the images can be saved for future analyzes. In addition, they can help understanding the cracking processes of FRC.

The tensile tests showed a more consistent behavior than the bending test results established by the codes. In any case, the methodology proposed supplies relevant information about the tensile behavior of FRC that could be compared with the constitutive models of the Standards, thus, providing reliability in the structural use of FRC.

Regarding the shear tests, it should be observed that for small slipping values the behavior of steel fiber reinforcement is better than that of polyolefin fibers due to the higher modulus of elasticity and the effect of the hooked end of the steel fibers. In all cases the Standards underestimated the shear strength for small sliding values in the range of $0.5 \mathrm{~mm}$. For higher sliding values the experimental and standard values are similar with a better behavior of polyolefin fibers as compared with steel fibers.

The video-extensometry of the shear tests allowed the assessment of the sliding and crack opening values at the crack discontinuity. Such values may be quite relevant for the study of the FRC behavior when subjected to shear according to the shear-friction model theories.

Moreover, the methodology proposed in this study provide the designer with values of shear strengths coming from push-off tests. It is important to remark that if these tests were not performed, the shear structural design would be developed through the use of residual strengths extracted from bending tests being the of shear reinforcement mechanisms entirely different from bending reinforcement mechanisms.

Acknowledgments: The authors gratefully acknowledge the financial support provided by the Ministry of Economy, Industry and Competitiveness of Spain by means of the Research Fund Project PID2019-108978RBC31. They also offer their gratitude to SIKA SAU for supplying the polyolefin fibers.

Conflicts of Interest: The authors declare no conflict of interest.

\section{References}

1. N. Banthia and J. Sheng, "Fracture toughness of micro-fiber reinforced cement composites," Cement and Concrete Composites, vol. 18, no. 4, pp. 251-269, 1996.

2. S. Grünewald, F. Laranjeira, J. Walraven, A. Aguado, and C. Molins, "Improved tensile performance with fiber reinforced self-compacting concrete," in High Performance Fiber Reinforced Cement Composites 6: Springer, 2012, pp. 51-58.

3. A. Blanco, P. Pujadas, A. de la Fuente, S. Cavalaro, and A. Aguado, "Application of constitutive models in European codes to RC-FRC," Construction and Building Materials, vol. 40, pp. 246-259, 2013.

4. P. Serna, S. Arango, T. Ribeiro, A. Núñez, and E. Garcia-Taengua, "Structural cast-in-place SFRC: technology, control criteria and recent applications in spain," Materials and structures, vol. 42, no. 9, pp. 1233-1246, 2009. 
5. M. G. Alberti, A. Enfedaque, J. C. Gálvez, and L. Pinillos, "Structural Cast-in-Place Application of Polyolefin Fiber-Reinforced Concrete in a Water Pipeline Supporting Elements," Journal of Pipeline Systems Engineering and Practice, vol. 8, no. 4, p. 05017002, 2017.

6. P. Serna, J. Á. López, H. Coll, E. Camacho, J. Navarro-Gregori, and F. Galán, "Pasarela de hormigón de muy alto rendimiento sobre el Barranco de las Ovejas (Alicante)," Hormigón y acero, vol. 66, no. 275, pp. 23-42, 2015.

7. J. Lancha, "FRC wind Towers," in 2nd FRC International Workshop Fiber Reinforced Concrete: from design to Structural Applications, 1st ACI-FIB Joint Workshop. Montreal, Canada, 2014.

8. International Federation for Structural Concrete (fib), The fib Model Code for Concrete Structures 2010. Lausanne, Switzerland: International Federation for Structural Concrete, 2010.

9. American Concrete Institute, 544.3R-08: Guide for Specifying, Proportioning, and Production of FiberReinforced Concrete. Farmington Hills, MI, USA: American Concrete Institute (ACI), 2008.

10. Consiglio Nazionale delle Riserche, Guide for the Design and Construction of Fibre-Reinforced Concrete Structures (National Research Council-Advisory Committee on Technical Recommendations for Construction. SN: CNR-DT). Rome, Italy: Consiglio Nazionale delle Riserche, , 2006.

11. (1992). Technologie des Stahlfaser-betons und Stahlfaserprit.

12. Spanish Minister of Public Works, Spanish Structural Concrete Code EHE-08. Madrid, Spain: Spanish Minister of Public Works, 2008.

13. M. di Prisco, G. Plizzari, and L. Vandewalle, "Fibre reinforced concrete: new design perspectives," Materials and Structures, vol. 42, no. 9, pp. 1261-1281, 2009.

14. A. A. Mirsayah and N. Banthia, "Shear strength of steel fiber-reinforced concrete," Materials Journal, vol. 99, no. 5, pp. 473-479, 2002.

15. E. Cuenca and P. Serna, "Failure modes and shear design of prestressed hollow core slabs made of fiberreinforced concrete," Composites Part B: Engineering, vol. 45, no. 1, pp. 952-964, 2013.

16. F. Ortiz Navas, J. Navarro-Gregori, G. L. Herdocia, P. Serna, and E. Cuenca, "An experimental study on the shear behaviour of reinforced concrete beams with macro-synthetic fibres," Construction and Building Materials, vol. 169, pp. 888-899, 2018.

17. E. Cuenca and P. Serna, "Shear behavior of prestressed precast beams made of self-compacting fiber reinforced concrete," Construction and Building Materials, vol. 45, pp. 145-156, 2013.

18. M. G. Alberti, A. Enfedaque, and J. C. Gálvez, "On the mechanical properties and fracture behavior of polyolefin fiber-reinforced self-compacting concrete," Construction and Building Materials, vol. 55, pp. 274288, 2014.

19. M. G. Alberti, A. Enfedaque, J. C. Gálvez, and Á. Picazo, "Recent advances in structural fibre-reinforced concrete focused on polyolefin-based macro-synthetic fibres," Materiales de Construcción, vol. 70, no. 337, p. e206, 2020-02-18 2020, doi: 10.3989/mc.2020.12418.

20. H. Aoude, M. Belghiti, W. D. Cook, and D. Mitchell, "Response of Steel Fiber-Reinforced Concrete Beams with and without Stirrups," ACI Structural Journal, vol. 109, no. 3, 2012.

21. Y.-K. Kwak, M. O. Eberhard, W.-S. Kim, and J. Kim, "Shear strength of steel fiber-reinforced concrete beams without stirrups," ACI Structural Journal, vol. 99, no. 4, pp. 530-538, 2002.

22. F. Minelli, A. Conforti, E. Cuenca, and G. Plizzari, "Are steel fibres able to mitigate or eliminate size effect in shear? " Materials and structures, vol. 47, no. 3, pp. 459-473, 2014.

23. C. European Committee for Standardization, "Test Method for Metallic Fiber Concrete. Measuring the Flexural Tensile Strength (Limit of Proportionality (LOP), Residual); EN14651:2007+A1," 2007.

24. RILEM, "Bending Test: Final Recommendations; RILEM TC-162-TDF," 2002.

25. E. Cuenca, J. Echegaray-Oviedo, and P. Serna, "Influence of concrete matrix and type of fiber on the shear behavior of self-compacting fiber reinforced concrete beams," Composites Part B: Engineering, vol. 75, pp. 135-147, 2015.

26. M. G. Alberti, A. Enfedaque, J. C. Gálvez, and E. Reyes, "Numerical modelling of the fracture of polyolefin fibre reinforced concrete by using a cohesive fracture approach," Composites Part B: Engineering, vol. 111, pp. 200-210, 2017.

27. I. Rodríguez. (2013) Diseño y caracterización de hormigones autocompactantes reforzados con fibras de acero. TFM. 
28. M. G. Alberti, A. Enfedaque, J. C. Gálvez, C. Álvarez, and Á. Picazo, "Moderate-strength concrete reinforced with polyolefin fibres: considerations and design of a competitive structural concrete.," DYNA, vol. 95, no. 3, pp. 322-326, 2020.

29. D. Lecompte et al., "Quality assessment of speckle patterns for digital image correlation," Optics and lasers in Engineering, vol. 44, no. 11, pp. 1132-1145, 2006.

30. Y. Su and Q. Zhang, "Quality Assessment of Speckle Patterns by Estimating RMSE," in International Digital Imaging Correlation Society: Springer, 2017, pp. 71-74.

31. S. Alam, A. Loukili, F. Grondin, and E. Rozière, "Use of the digital image correlation and acoustic emission technique to study the effect of structural size on cracking of reinforced concrete," Engineering Fracture mechanics, vol. 143, pp. 17-31, 2015.

32. M. G. Alberti, A. Enfedaque, J. C. Gálvez, and V. Agrawal, "Fibre distribution and orientation of macrosynthetic polyolefin fibre reinforced concrete elements," Construction and Building Materials, vol. 122, pp. 505-517, 2016.

33. R. Cintron and V. Saouma, "Strain measurements with the digital image correlation system Vic-2D," System, vol. 106, p. 2D, 2008.

34. Á. Picazo, J. C. Gálvez, M. G. Alberti, and A. Enfedaque, "Assessment of the shear behaviour of polyolefin fibre reinforced concrete and verification by means of digital image correlation," Construction and Building Materials, vol. 181, pp. 565-578, 8/30/ 2018.

35. J. C. Walraven, "Aggregate interlock: a theoretical and experimental analysis," 1980.

36. M. N. Fardis and O. Buyukozturk, "Shear transfer model for reinforced concrete," Journal of Engineering Mechanics, vol. 105, no. ASCE 14507 Proceeding, 1979.

37. A. Picazo, "Experimental and numerical study of the shear behaviour of polyolefin and steel fiber reinforced concrete", PhD Thesis (In Spanish), Universidad Politécnica Madrid, 468 pág, 2020. 